Article

\title{
Adsorption Behavior and Electron Structure Engineering of Pd-Based Catalysts for Acetylene Hydrochlorination
}

\author{
Yaqing Cen ${ }^{1}$, Yuxue Yue ${ }^{1}$, Saisai Wang ${ }^{1}$, Jinyue Lu ${ }^{1}$, Bolin Wang ${ }^{1}$, Chunxiao Jin ${ }^{1}$, \\ Lingling Guo ${ }^{1}$, Zhong-Ting $\mathrm{Hu}^{2}$ and Jia Zhao ${ }^{1, *}$ \\ 1 State Key Laboratory Breeding Base of Green Chemistry-Synthesis Technology, Industrial Catalysis Institute, \\ Zhejiang University of Technology, Hangzhou 310014, China; cenyq@zjut.edu.cn (Y.C.); \\ yueyuxue@outlook.com (Y.Y.); wangss412728@outlook.com (S.W.); ljy1195330324@outlook.com (J.L.); \\ wb1501028@outlook.com (B.W.); a903141337@outlook.com (C.J.); lguo@zjut.edu.cn (L.G.) \\ 2 Department of Environmental Engineering, Zhejiang University of Technology, Hangzhou 310014, China; \\ zthu@zjut.edu.cn \\ * Correspondence: jiazhao@zjut.edu.cn; Tel.: +86-571-8887-1565
}

Received: 17 November 2019; Accepted: 20 December 2019; Published: 24 December 2019

\begin{abstract}
Adsorption and activation for substrates and the stability of Pd species in Pd-based catalysts are imperative for their wider adoption in industrial and practical applications. However, the influence factor of these aspects has remained unclear. This indicates a need to understand the various perceptions of the structure-function relationship that exists between microstructure and catalytic performance. Herein, we revisit the catalytic performance of supported-ionic-liquid-phase stabilized Pd-based catalysts with nitrogen-containing ligands as a promoter for acetylene hydrochlorination, and try to figure out their regulation. We found that the absolute value of the differential energy, $\left|\mathrm{E}_{a d s}\left(\mathrm{C}_{2} \mathrm{H}_{2}\right)-\mathrm{E}_{a d s}(\mathrm{HCl})\right|$, is negative correlated with the stability of palladium catalysts. These findings imply that the optimization of the electron structure provides a new strategy for designing highly active yet durable Pd-based catalysts.
\end{abstract}

Keywords: palladium catalysts preparation; N-containing ligands; ionic liquids; electron structure; adsorption behavior; hydrochlorination

\section{Introduction}

Poly vinyl chloride (PVC), as the most commonly used thermoplastic, is used in different kinds of fields in modern society [1-3]. There are two basic ways in which vinyl chloride monomer (VCM) can be widely produced: the hydrochlorination of acetylene and the oxychlorination of ethylene [2-5]. For acetylene hydrochlorination, $\mathrm{Hg}$-based catalysts have been used as the main industrial catalysts for the production of VCM. However, mercuric component is volatile under the reaction conditions and thus do harmful to ecological environment and human beings [1-6]. Thus, replace of toxic Hg-based catalysts with non-mercury-containing alternatives would be significantly beneficial in this process [6-17]. A lot of effort is being spent on improving these weaknesses. Among them, gold-based catalysts are good candidates for commercial success using this approach [1,3], since the reaction conditions are mild for $\mathrm{Au}$ and also present comparable catalytic properties to $\mathrm{Hg}$. However, there is still an ongoing research investigating alternative activity catalysts to synthesize VCM by acetylene hydrochlorination approach [18-35].

Recent studies have shown that Pd supported catalysts could be an efficient, low-cost, mercury-free alternative for acetylene hydrochlorination [29,36-43]. However, the inherent volatilization of $\mathrm{Pd}$ component limits the use of Pd-based catalysts for producing VCM [36-43]. We have previously reported 
a supported-ionic-liquid-phase (SILP) Pd catalysts (Pd-IL/AC) for the acetylene hydrochlorination [29]. The presence of ionic liquids proved to be formed a more active and durable catalyst, which furnishes significant promotion on Pd species dispersion, valence states and structure stability, deposition reduction and thermal stability. Recently investigators have examined the effects of $\mathrm{NH}_{4} \mathrm{Cl}$ on $\mathrm{Pd}$ catalyst, which greatly enhanced the adsorption behavior for reactants via the construction of a micoelectronic environment [30]. It is now well established that adsorption and reaction behavior can be controlled by ionic liquids and $\mathrm{NH}_{4} \mathrm{Cl}$ ligands. However, the influence of these additives on the active site structures and reaction process have remained unclear. This indicates a need to understand the various perceptions of the structure-function relationship that exists between the microstructure and catalytic performance of Pd-based catalysts. Herein, we synthesized a series of $\mathrm{N}$-containing ligands $\mathrm{Pd}$-based catalysts with ionic liquids as medium. The addition of $\mathrm{N}$-containing ligands can selectivity modify the adsorption energy for $\mathrm{HCl}$ and $\mathrm{C}_{2} \mathrm{H}_{2}$ on $\mathrm{Pd}$ active sites. Among the various $\mathrm{N}$-containing ligands, $\mathrm{NH}_{4} \mathrm{Cl}$ is able to furnish Pd-based catalysts in a higher catalytic activity and durability. Furthermore, by designing differential adsorption energy, $\left|\mathrm{E}_{a d s}\left(\mathrm{C}_{2} \mathrm{H}_{2}\right)-\mathrm{E}_{\text {ads }}(\mathrm{HCl})\right|$, which features the difference of adsorption intensity for $\mathrm{HCl}$ and $\mathrm{C}_{2} \mathrm{H}_{2}$, a bridge between $\left|\mathrm{E}_{a d s}\left(\mathrm{C}_{2} \mathrm{H}_{2}\right)-\mathrm{E}_{\text {ads }}(\mathrm{HCl})\right|$ and $\mathrm{Pd}$ catalysts performance can effectively be established to achieve concurrently high catalytic durability. Following this trail, we further explored the effect of nitrogen ligands on the electron structure of Pd-based catalysts. Results illustrate that nitrogen-containing ligands, along with ionic liquids strongly control the electron density of metal center and obviously improve the catalytic properties.

\section{Results and Discussion}

\subsection{Catalytic Performance of Pd-Based Catalysts}

First, $\mathrm{NH}_{4} \mathrm{Cl}$ was used as the representative $\mathrm{N}$-ligands to evaluate the catalytic performance of $\mathrm{Pd}-\mathrm{N}-\mathrm{IL} / \mathrm{AC}$ catalysts in acetylene hydrochlorination reaction. The investigated catalysts, including AC, Pd/AC, Pd-IL/AC Pd-A/AC, A/AC, IL/AC, A-IL/AC, Pd-0.5A-IL/AC, Pd-1A-IL/AC, Pd-2A-IL/AC, and Pd-3A-IL/AC have been performed at a temperature of $160^{\circ} \mathrm{C}$ and the GHSV of $1000 \mathrm{~h}^{-1}$. From Figure $1 \mathrm{a}$, we note that catalysts without ionic liquids exhibits almost no acetylene conversion after $10 \mathrm{~h}$. Although in the presence of $\mathrm{NH}_{4} \mathrm{Cl}$ promoter the $\mathrm{Pd}-\mathrm{A} / \mathrm{AC}$ catalyst exhibits a relatively high initial activity than $\mathrm{Pd} / \mathrm{AC}$ catalyst, the deactivation rate was extremely fast. However, when we used the Pd-IL/AC catalyst, which loaded with $20 \% \mathrm{IL}$, the conversion of acetylene rises to $80 \%$, meanwhile, furnishes an excellent stability. The further used Pd-A-IL/AC catalyst with $0.5 \mathrm{NH}_{4} \mathrm{Cl}$ promoted the conversion rises to $85.3 \%$. With the rising loading of $\mathrm{NH}_{4} \mathrm{Cl}$, the conversion of acetylene increases obviously. The catalysts, including Pd-1A-IL/AC, Pd-2A-IL/AC, and Pd-3A-IL/AC (0.5, 1, 2 and 3 are the molar multiple of $\mathrm{Pd}$ ) achieve the acetylene conversion to $88 \%, 91.1 \%$, and $89.3 \%$ at $10 \mathrm{~h}$, respectively. The conversion of acetylene reaches a maximum as the amount of $\mathrm{NH}_{4} \mathrm{Cl}$ is up to 2, indicating that 2 is the optimal addition amount of $\mathrm{NH}_{4} \mathrm{Cl}$ for Pd-A-IL/AC catalyst. However, for the metal-free catalysts, A/AC and IL/AC, the conversion of acetylene is only $2.28 \%$ and $1.21 \%$. Thus, the excellent catalytic performance over Pd-A-IL/AC is attributed to the synergistic effect among $\mathrm{NH}_{4} \mathrm{Cl}$, ILs and Pd components. All these catalysts furnished almost $100 \%$ selectivity to VCM.

The catalysts with other three kinds N-ligands additive were also performed in the reaction of acetylene hydrochlorination. As is shown in Figure 1b, the catalytic performance of Pd-2A-IL/AC, Pd-2EDA-IL/AC, Pd-2PR-IL/AC, and Pd-2PD-IL/AC were performed. The initial conversion of acetylene over these catalysts achieves at $97.2 \%, 97 \%, 90.3 \%$, and $91.1 \%$, respectively. Interestingly, all these catalysts exhibit higher stability than Pd-IL/AC catalyst, indicating that these N-containing ligands indeed can enhance the stability of supported-ionic-liquids-phase Pd catalyst.

Different space velocity tests were also performed to further to investigate the catalytic ability of Pd-2A-IL/AC catalyst in the reaction of acetylene hydrochlorination. As is shown in Figure 1c, the acetylene conversion attained $99 \%$ and $82 \%$ as the GHSV increases from $50 \mathrm{~h}^{-1}$ to $1480 \mathrm{~h}^{-1}$ at $160{ }^{\circ} \mathrm{C}$. We have demonstrated that the designed Pd-A-IL/AC catalyst is adequate for acetylene hydrochlorination in a wide space velocity range. 

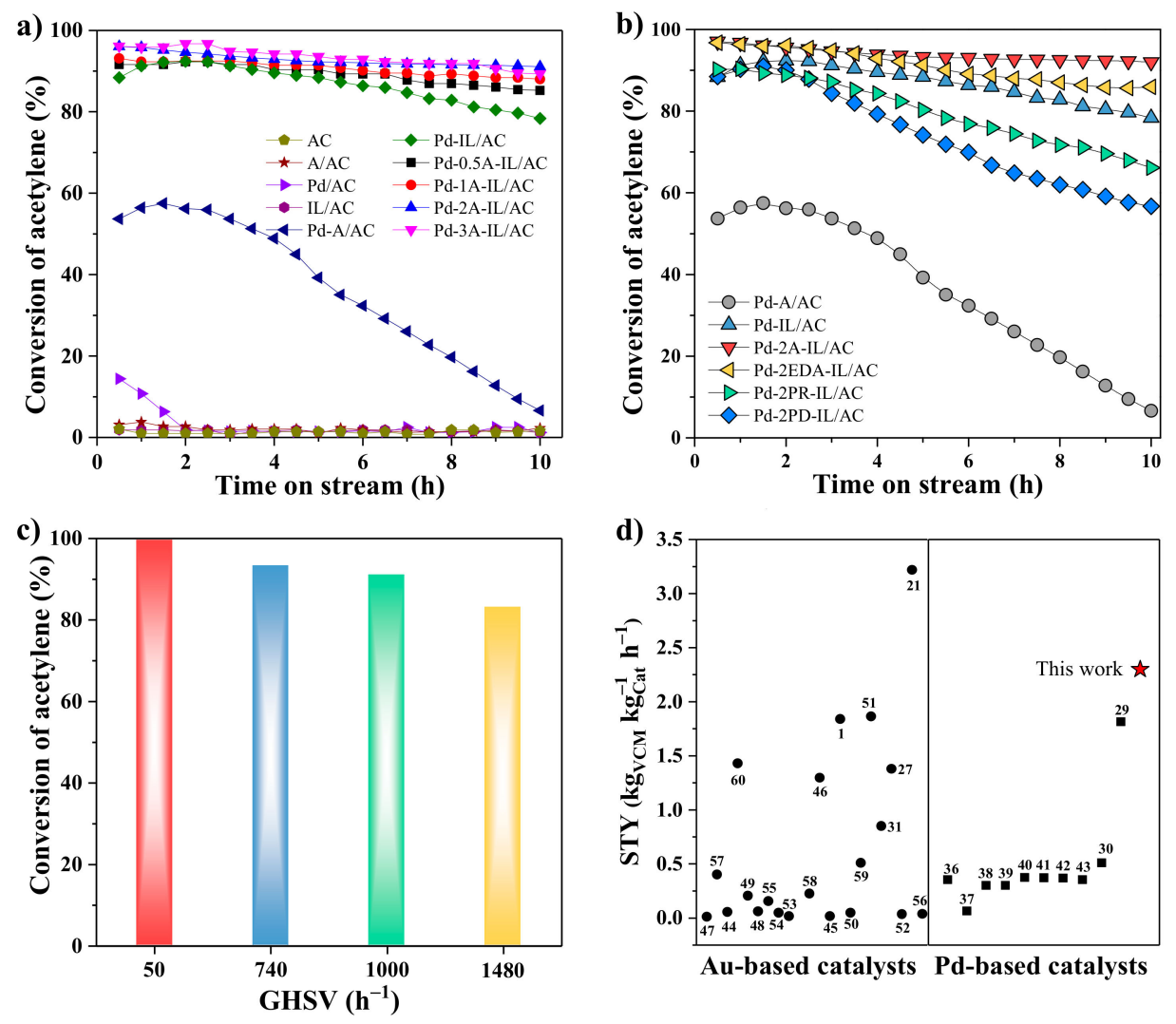

Figure 1. $(\mathbf{a}, \mathbf{b})$ Conversion of acetylene over different catalysts. Reaction conditions: $\mathrm{T}=160{ }^{\circ} \mathrm{C}, \mathrm{GHSV}$ $=1000 \mathrm{~h}^{-1}$, and $\mathrm{V}_{\mathrm{HCl}} / \mathrm{V}_{\mathrm{C} 2 \mathrm{H} 2}=1.2$. (c) Catalytic performance of Pd-2A-IL/AC catalyst at different space velocity. (d) The calculated STY $\left(\mathrm{kg}_{\mathrm{VCM}} \mathrm{h}^{-1} \mathrm{~kg}_{\mathrm{Cat}}{ }^{-1}\right)$ values of Pd- and Au-based catalysts from relevant literatures $[1,21,27,29-31,36-60]$.

To comprehensive illustrate the catalytic performance evolution of the active phase for Pd-2A-IL/AC catalyst, the space time yield (STY) were discussed for relevant literature reported (Table S1) acetylene hydrochlorination catalysts $[1,21,27,29-31,36-60]$, and the results were displayed in Figure $1 \mathrm{~d}$. In the case of catalysts with ionic liquids, the results show that Pd-IL/AC and Pd-2A-IL/AC have better catalytic activity and higher STY, while the presence of N-containing ligands and ionic liquids together result in an even greater enhance in catalytic activity. The enhancement of catalytic ability is attributed to the improvement on the intrinsic electron properties of the catalyst, which implies a synergic effect for $\mathrm{Pd}$ active sites by $\mathrm{N}$-containing ligands and ionic liquids that results in a highly active catalyst. Surprisingly, the STY of Pd-2A-IL/AC $\left(2.3 \mathrm{~kg}_{\mathrm{VCM}} \mathrm{h}^{-1} \mathrm{~kg}_{\mathrm{Cat}^{-1}}\right)$ was higher than for benchmark Au/AC $\left(1.86 \mathrm{kgVCM} \mathrm{h}^{-1} \mathrm{~kg}_{\mathrm{Cat}}{ }^{-1}\right)$ and commercial-like $\mathrm{Na}_{3} \mathrm{Au}\left(\mathrm{S}_{2} \mathrm{O}_{3}\right)_{2} / \mathrm{AC}\left(1.84 \mathrm{~kg}_{\mathrm{VCM}} \mathrm{h}^{-1} \mathrm{~kg}_{\mathrm{Cat}}{ }^{-1}\right)$ catalysts, and was less active than the $\mathrm{Au}-\mathrm{Cu}-\mathrm{IL} / \mathrm{AC}$ catalyst.

\subsection{Characterization of Pd-Based Catalysts}

A lot of studies have made great progress towards increased resistance against active component leach of $\mathrm{Pd}$ catalysts. Wang et al. introduced $\mathrm{K}$ and $\mathrm{NH}_{4} \mathrm{~F}$ promoters in $\mathrm{Pd} / \mathrm{HY}$ catalyst. The presence of $\mathrm{K}$ and $\mathrm{NH}_{4} \mathrm{~F}$ promoters exhibit a good effect on the acidity on the surface of catalyst and effectively inhibit the run off of Pd component [38-43]. Hu et al. reported an (NPs)/surfactant ionic liquids system and constructed an effective redox cycle in catalytic system [61]. The presence of ionic liquids and redox cycle have an instructive effect on the stabilization of Pd component. Zhao et al. synthesized a Pd-IL/AC catalyst by adopting SILP system [29]. The catalyst exhibits a stable catalytic performance within $500 \mathrm{~h}$. He et al. reported a $\mathrm{NH}_{4}{ }^{+}$promoted palladium catalyst which can enhance the stability of Pd component and improve the adsorption ability of $\mathrm{HCl}$ molecule [30]. Obviously, ionic liquids 
and nitrogen-containing ligands play an important role in improving the catalytic performance of Pd catalyst.

To get a further understanding of the effects of N-containing ligands on structure and stability, fresh and used Pd-2A-IL/AC catalysts are characterized by TEM, XRD, and XPS. Figure 2 displays the HAADF-STEM images of fresh and used Pd-based catalysts. As is shown, for fresh Pd-IL/AC (Figure 2b), the small amount of dispersed particles was detected on support, less than that on Pd/AC (Figure 2a). For Pd-2A-IL/AC (Figure 2c), there appear almost no Pd cluster or nanoparticles on support compare with fresh $\mathrm{Pd} / \mathrm{AC}$ and $\mathrm{Pd}-\mathrm{IL} / \mathrm{AC}$, indicating that $\mathrm{NH}_{4} \mathrm{Cl}$ can further enhance the dispersion of $\mathrm{Pd}$ components on the support. The Pd species in fresh $\mathrm{NH}_{4} \mathrm{Cl}$ promoted $\mathrm{Pd} / \mathrm{AC}$ catalyst was exists in the form of single atoms over activated carbon surface, which has been proved by He et al. and further confirmed our observations. For the used Pd/AC (Figure 2d), there appear more particles dispersed on the support, much larger than that on the used Pd-IL/AC (Figure 2e), which indicats a certain aggregation of $\mathrm{Pd}$ components during the reaction. However, over the used Pd-2A-IL/AC (Figure 2f), no distinguishable Pd particles were detected. XRD results of fresh and used Pd/AC (Supplementary Figure S1), Pd-IL/AC (Supplementary Figure S1) and Pd-2A-IL/AC (Figure 3a) catalysts can also prove that the co-addition of ionic liuids and ligands could further enhance the stability of $\mathrm{Pd}$ species during the reaction process. For the used Pd/AC and Pd-IL/AC catalysts both presented distinguishable diffraction peaks in XRD profiles as is shown in Figure S1, however, the XRD profile of used Pd-2A-IL/AC catalysts still exhibited amorphous peaks that corresponded to activated carbon. Meanwhile, the co-addition of ionic liuids and ligands improves the dispersion of active components (Pd-A-IL) on support compared with Pd-IL/AC catalysts, which can be confirmed by the BET results in Table 1, as the surface area and pore volume of Pd-A-IL/AC series catalysts $\left(>688 \mathrm{~m}^{2} \mathrm{~g}^{-1}\right)$ were higher than Pd-IL/AC catalyst $\left(653 \mathrm{~m}^{2} \mathrm{~g}^{-1}\right)$. These results show that $\mathrm{NH}_{4} \mathrm{Cl}$ can not only improve the dispersion of $\mathrm{Pd}$ species in the catalysts, but also inhibit to some extent the aggregation of Pd species during the reaction, which can be further verified by EDS mapping in Figure 3.
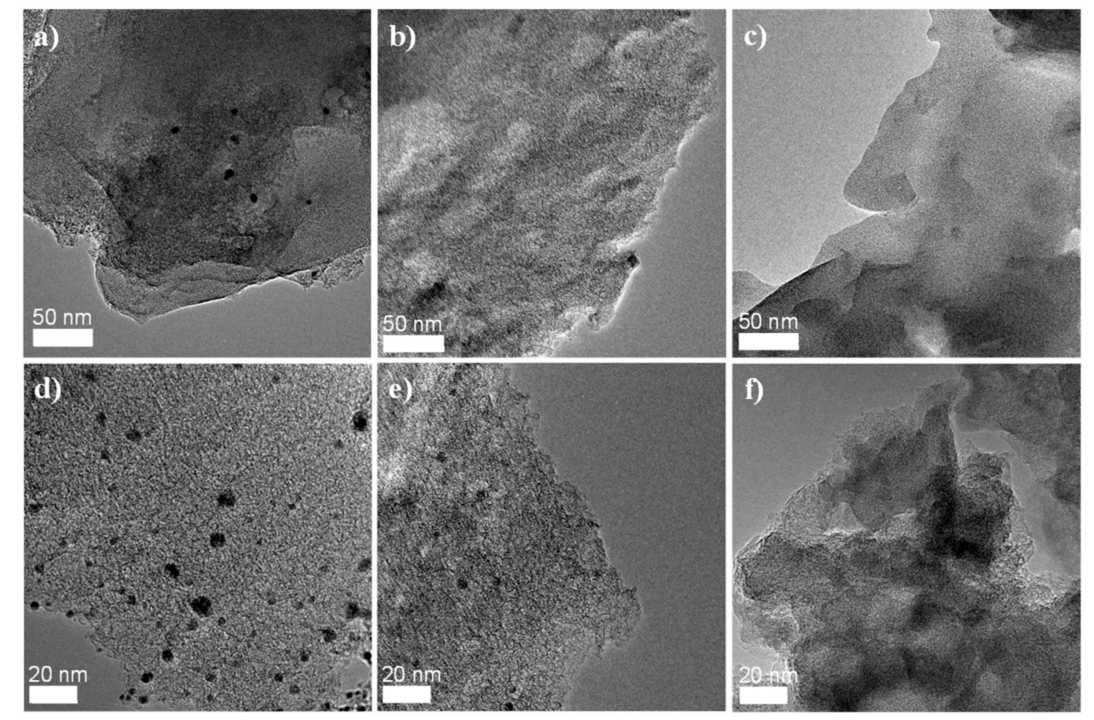

Figure 2. HAADF-STEM images of fresh (a) Pd/AC (b) Pd-IL/AC (c) Pd-2A-IL/AC and used (d) Pd/AC (e) Pd-IL/AC (f) Pd-2A-IL/AC catalysts.

To further investigate the enhancement of $\mathrm{NH}_{4} \mathrm{Cl}$ on Pd catalyst stability. XRD and XPS analysis were also performed. Figure 3 a shows the XRD results, we can see that no significant metallic $\mathrm{Pd}$ crystals were formed in the Pd-2A-IL/AC catalyst. Supplementary Figure S2 compares the XPS results of fresh and used $\mathrm{Pd} / \mathrm{AC}$ and $\mathrm{Pd}-\mathrm{Il} / \mathrm{AC}$ catalysts, the fresh and used $\mathrm{Pd} / \mathrm{AC}$ catalysts both exhibited $\mathrm{Pd}^{0}$ peaks at $334.6 \mathrm{eV}$, and the $\mathrm{Pd}^{0}$ species fraction used in $\mathrm{Pd} / \mathrm{AC}$ were slightly higher than in fresh $\mathrm{Pd} / \mathrm{AC}$ catalyst. For the Pd-IL/AC catalyst, both fresh and used catalysts exhibited $\mathrm{Pd}^{2+}$ peaks and 
no $\mathrm{Pd}^{0}$ peaks were detected, which was conflicted with that of TEM and XRD observations, this may ascribe to that the $\mathrm{Pd}^{0}$ fraction was too low to detect by XPS or the fraction difference between $\mathrm{Pd}^{2+}$ and $\mathrm{Pd}^{0}$ was too large. The XPS spectra for the Pd (Figure $3 \mathrm{~b}$ ) of fresh and used Pd-2A-IL/AC samples showed a main peak at $337.4 \mathrm{eV}$, suggesting that $\mathrm{Pd}$ species exhibit positive charges $\left(\mathrm{Pd}^{2+}\right)$ rather than $\mathrm{Pd}^{0}$. Zhao et al. has reported that the introduce of ionic liquids (BMImCl) can dramatically enhance the structure of $\mathrm{Pd}$ species and valence states in acetylene hydrochlorination stability [29]. This is indicative of the fact that Pd-2A-IL/AC catalyst also has an excellent stability on the Pd valence states as well as Pd dispersion.
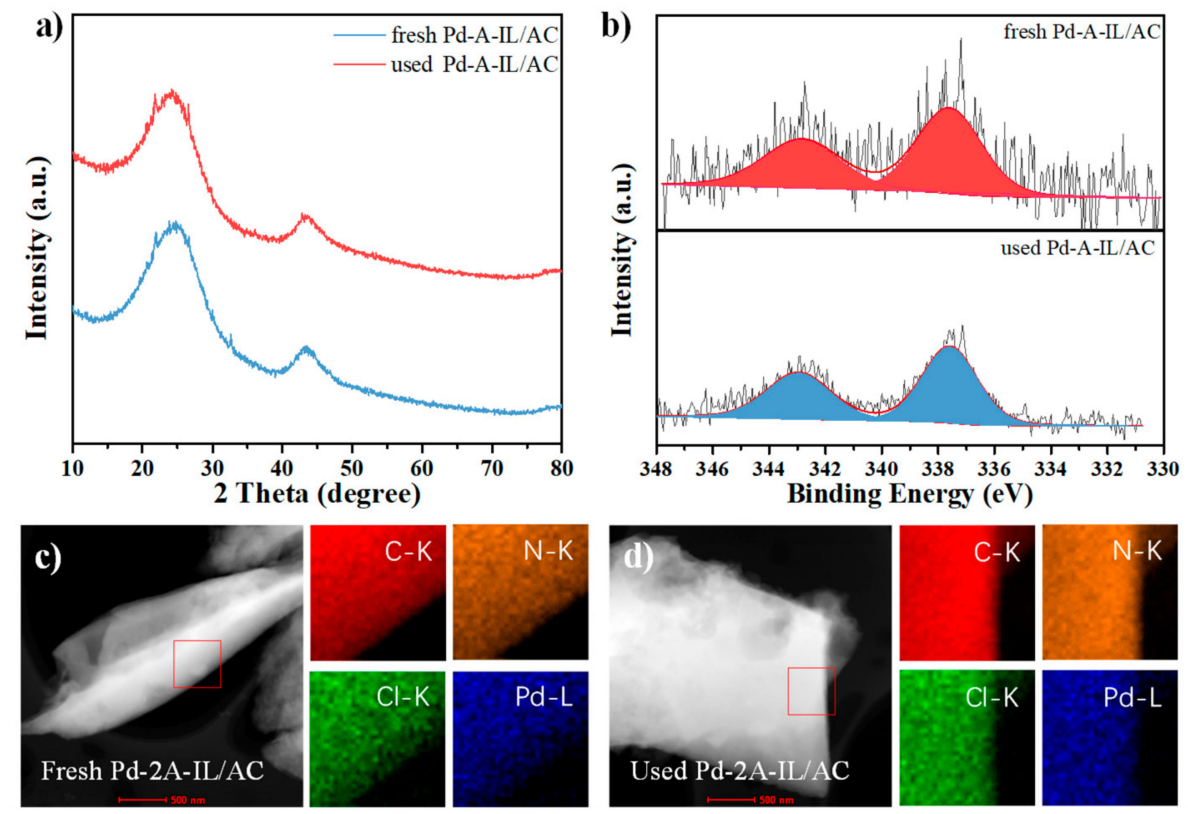

Figure 3. Characterization of fresh and used Pd-A-IL/AC catalysts. (a) XRD patterns. (b) XPS spectra. HAADF-STEM and EDS Mappings of (c) fresh and (d) used Pd-2A-IL/AC catalyst.

Table 1. Pore structure parameters of catalysts.

\begin{tabular}{ccc}
\hline Catalysts & Surface Area $\left(\mathbf{m}^{\mathbf{2}} \mathbf{g}^{\mathbf{- 1}}\right)$ & Pore Volume $\left(\mathbf{c m}^{\mathbf{3}} \mathbf{g}^{-\mathbf{1}}\right)$ \\
\hline AC & 1215 & 0.67 \\
Pd/AC & 1179 & 0.62 \\
Pd-IL/AC & 653 & 0.36 \\
Pd-A/AC & 1154 & 0.60 \\
Pd-0.5A-IL/AC & 688 & 0.37 \\
Pd-1A-IL/AC & 732 & 0.40 \\
Pd-2A-IL/AC & 747 & 0.41 \\
Pd-3A-IL/AC & 705 & 0.37 \\
\hline
\end{tabular}

Previous research has proved that cationic Pd species works as catalytic active site in hydrochlorination catalysts $[29,30,36]$. However, the leaching of $\mathrm{Pd}$ active component (in the form of $\mathrm{PdCl}_{2}-\mathrm{C}_{2} \mathrm{H}_{2}$ ) and the reduction of $\mathrm{Pd}^{2+}$ species during acetylene hydrochlorination reaction has also been widely accepted [36,62-64]. Surprisingly, the addition of ionic liquids and N-containing additives can not only improve the distribution of Pd complex, but also enhance the thermal and chemical stability of Pd species in reaction. For one hand, Pd species exists entirely in the form of $\mathrm{Pd}^{2+}$ in the fresh and used Pd-2A-IL/AC catalyst, indicating that the synergistic effect of N-containing ligands and ionic liquids can greatly enhanced the stability of Pd valence as well as dispersion. For another hand, as listed in Table 2, the introducing of ionic liquids reduces the leaching of Pd component by a large margin. The loss of Pd component was controlled under 10\%, which was one of fifth in comparison of $\mathrm{Pd} / \mathrm{AC}$ catalyst. Meanwhile, the continued addition of N-containing ligands further inhibited the 
leaching of Pd component, for the loss ratio of Pd in Pd-2A-IL/AC catalyst was deceased to $3.9 \%$, which was half of Pd-IL/AC catalyst (8.2\%).

Table 2. Pd content in the fresh and used Pd-based catalysts based on the ICP analysis.

\begin{tabular}{ccccc}
\hline \multirow{2}{*}{ Catalysts } & \multirow{2}{*}{ Nominal Loading (wt\%) } & \multicolumn{2}{c}{ Results of ICP (wt\%) } & \multirow{2}{*}{ Loss of Pd (wt $\%)$} \\
\cline { 3 - 4 } & & Fresh & Used & \\
\hline Pd/AC & 0.5 & 0.54 & 0.28 & 48.1 \\
Pd-IL/AC & 0.5 & 0.49 & 0.45 & 8.2 \\
Pd-2A-IL/AC & 0.5 & 0.51 & 0.49 & 3.9 \\
Pd-A/AC & 0.5 & 0.52 & 0.40 & 23.1 \\
Pd-2EDA-IL/AC & 0.5 & 0.49 & 0.47 & 4.1 \\
Pd-2PR-IL/AC & 0.5 & 0.47 & 0.45 & 4.3 \\
Pd-2PD-IL/AC & 0.5 & 0.51 & 0.48 & 5.9 \\
\hline
\end{tabular}

High angle annular dark-field scanning transmission electron microscope (HAADF-STEM) and energy-dispersive spectrum (EDS) mapping revealed that Palladium, Nitrogen, and Chlorine elements were homogeneously distributed over the fresh and used Pd-A-IL/AC catalysts (Figure 3c,d) $[21,27,29,30,65]$. Furthermore, the EDS-determined $\mathrm{N}$ content on the used Pd-A-IL/AC was ca. $2.07 \mathrm{wt} \%$ (Table 3), which is, almost consistent with that of fresh Pd-2A-IL/AC catalyst $(2.05 \mathrm{wt} \%)$, confirming that the $\mathrm{N}$-ligand exist steadily during the reaction. On the basis of the above discussion, unambiguously, the stability of Pd component was greatly improved as expected. It is speculated that the microelectronic environment of active $\mathrm{Pd}^{2+}$ center was changed and the adsorption behavior of $\mathrm{Pd}$ species was enhanced via the synergistic effect of $\mathrm{NH}_{4} \mathrm{Cl}$ and ionic liquids, which will be further discussed in the following part.

Table 3. Quantified EDS data for the fresh and used Pd-2A-IL/AC catalysts.

\begin{tabular}{cccccc}
\hline \multirow{2}{*}{ Catalysts } & \multicolumn{5}{c}{ Elemental Composition (wt\%) } \\
\cline { 2 - 6 } & Pd 3d & C 1s & O 1s & C1 2p & N 1s \\
\hline Fresh & 0.43 & 94.74 & 1.10 & 1.68 & 2.05 \\
Used & 0.36 & 94.59 & 1.22 & 1.76 & 2.07 \\
\hline
\end{tabular}

\subsection{Stability and Coke Deposition of Pd-2A-IL/AC Catalyst}

As one of the main reasons for catalyst deactivation, coke deposition especially occurred on metal-based catalyst like Pd catalyst. Aiming to study the coke deposition for the Pd-2A-IL/AC catalyst, we performed TGA measurements. Figure 4a shows the TGA results, we can see that both the fresh and used Pd-2A-IL/AC have a slight weight loss before $150{ }^{\circ} \mathrm{C}$, due to the desorption of water. Generally, in the temperature range of $150-400{ }^{\circ} \mathrm{C}$, the weight loss can be ascribed to the burning of coke. However, the decomposition temperature of 1-butyl-3-methylimidazolium chloride is about $254{ }^{\circ} \mathrm{C}$. Therefore, in the temperature range of $150-254{ }^{\circ} \mathrm{C}$, the weight loss for the used catalyst is ascribed to the coke deposition. According to the profile shown in Figure $4 \mathrm{~b}$, the coke deposition amount for the used Pd-2A-IL/AC catalyst is $1.16 \%$. Table 4 lists the coke deposition amounts on the used Pd/AC, Pd-IL/AC and various Pd-A-IL/AC catalysts. For the Pd-A-IL/AC catalysts, the amount of coke deposition decreases with the increase doping content of $\mathrm{NH}_{4} \mathrm{Cl}$, with the lowest amount of $1.09 \%$ on the used Pd-1A-IL/AC catalyst. All N-containing ligands doping supported ionic liquids Pd-based catalysts show lower coke deposition amount than that of Pd/AC and Pd-IL/AC catalysts. It illustrates that the co-addition of ionic liquids and $\mathrm{N}$-containing ligands can efficiently inhibit coke deposition on the Pd based catalyst. 

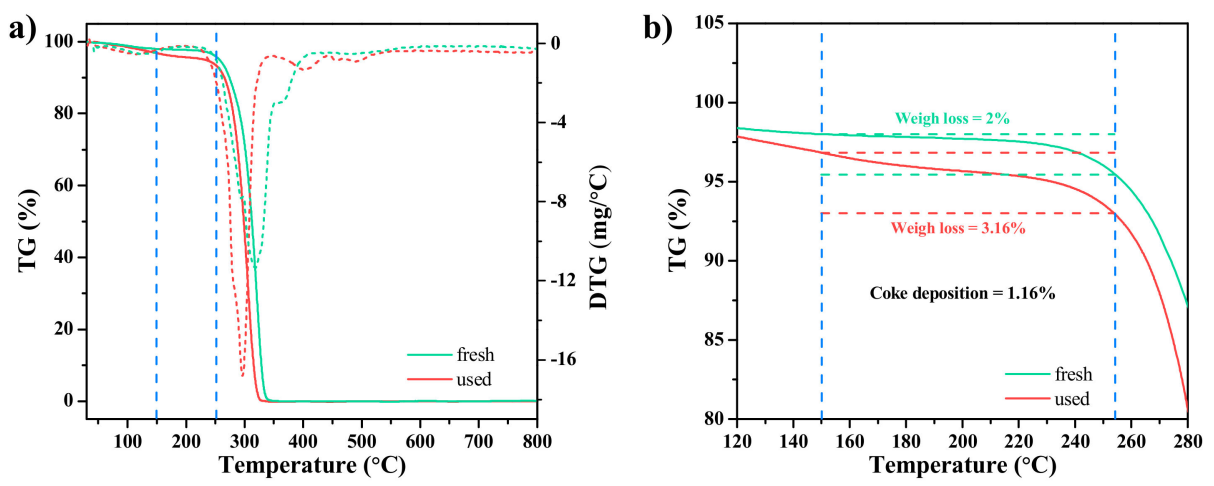

Figure 4. (a,b) TGA and DTG curves of the fresh and used Pd-2A-IL/AC catalysts.

Table 4. Coke deposition amount on used Pd-based catalysts surface.

\begin{tabular}{cc}
\hline Catalysts & Coke Deposition Amount $^{\mathbf{1}} \mathbf{( \% )}$ \\
\hline Pd/AC & 6.87 \\
Pd-IL/AC & 2.12 \\
Pd-0.5A-IL/AC & 2.30 \\
Pd-1A-IL/AC & 1.09 \\
Pd-2A-IL/AC & 1.16 \\
Pd-3A-IL/AC & 1.13 \\
Pd-2PR-IL/AC & 1.28 \\
Pd-2EDA-IL/AC & 1.61 \\
Pd-2PD-IL/AC & 1.33 \\
\hline Calculated according to TG profiles in the temperature range of $150-254^{\circ} \mathrm{C}$.
\end{tabular}

\subsection{DFT Calculation}

The strong adsorption capacity for acetylene leads to the serious deactivation of metal catalysts in the form of coke deposition, reduction and active components leaching $[36,62,63]$. To surmount the intrinsic limitations of typical palladium catalysts in acetylene hydrochlorination (i.e., leaching of Pd component), studies have focused on the modulation of the catalyst formulation, including carrier screening/doping and additive adding, to improve their durability. However, the intrinsic properties that influence the activity and stability of Pd catalysts in acetylene hydrochlorination have not been studied yet. Following this trail, we studied above discussed four nitrogen-containing-ligands (Figure 5) modified Pd-based catalysts via DFT calculation to figure out their regulation principle and the results were shown in Figure 6. From Figure 6a and Table S2, we notice that the addition of $\mathrm{NH}_{4} \mathrm{Cl}$ or ionic liquids both can decreased the acetylene adsorption energy and the co-addition of nitrogen-containing ligands and ionic liquids can further modulated the adsorption behavior for acetylene. In particular, the addition of $\mathrm{N}$-ligands can flexibly adjust the absorption properties for hydrogen chloride. It is well known that the strong adsorption of acetylene often leads to the loss and reduction of metal species, therefore, the relative low acetylene adsorption energy $\left(\mathrm{E}_{a d s}\left(\mathrm{C}_{2} \mathrm{H}_{2}\right)\right)$ and moderate hydrochloride adsorption energy $\left(\mathrm{E}_{a d s}(\mathrm{HCl})\right)$ would beneficial to the catalytic performance and durability of catalysts. Figure 6 a also shows a correlation between adsorption energies and catalytic activity of Pd-based catalysts. Without exception, compared with $\mathrm{Pd} / \mathrm{AC}$ and $\mathrm{Pd}-\mathrm{A} / \mathrm{AC}$, the catalysts with ionic liquids furnish higher VCM formation rate, and the co-addition of nitrogen-containing ligands and ionic liquids further improves the formation rate. 


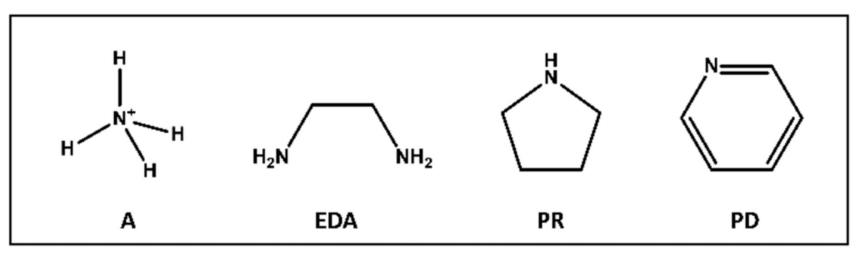

Figure 5. The molecular structure of the four nitrogen-containing ligands.
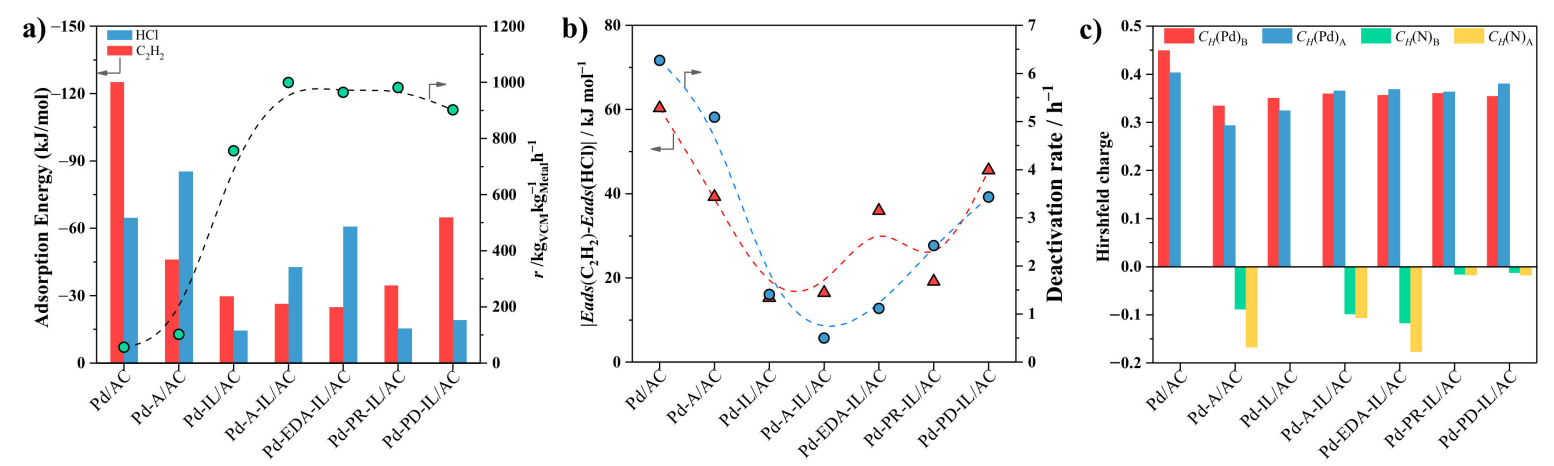

Figure 6. (a) Rate of VCM formation versus the adsorption energy of acetylene and hydrogen chloride for investigated catalysts. (b) Deactivation rate versus $\left|\mathrm{E}_{a d s}\left(\mathrm{C}_{2} \mathrm{H}_{2}\right)-\mathrm{E}_{a d s}(\mathrm{HCl})\right|$ for investigated catalysts. (c) Hirshfeld charge of $\mathrm{Pd}$ atoms $\left(\mathrm{C}_{H}(\mathrm{Pd})\right)$ and $\mathrm{N}$ atoms $\left(\mathrm{C}_{H}(\mathrm{~N})\right.$, where $\mathrm{N}$ is from $\mathrm{N}$-containing ligands) before $\left(\mathrm{C}_{H}(\mathrm{Pd})_{\mathrm{B}}, \mathrm{C}_{H}(\mathrm{~N})_{\mathrm{B}}\right)$ and after $\left(\mathrm{C}_{H}(\mathrm{Pd})_{\mathrm{A}}, \mathrm{C}_{H}(\mathrm{~N})_{\mathrm{A}}\right)$ acetylene adsorption.

Moreover, we evaluated the catalytic properties utilizing $\left|\mathrm{E}_{a d s}\left(\mathrm{C}_{2} \mathrm{H}_{2}\right)-\mathrm{E}_{\text {ads }}(\mathrm{HCl})\right|$ as a unified parameter to explain the intrinsic catalytic stability. The $\left|\mathrm{E}_{a d s}\left(\mathrm{C}_{2} \mathrm{H}_{2}\right)-\mathrm{E}_{\text {ads }}(\mathrm{HCl})\right|$ of the obtained Pd-based catalysts were carefully examined by DFT. Surprisingly, $\left|\mathrm{E}_{a d s}\left(\mathrm{C}_{2} \mathrm{H}_{2}\right)-\mathrm{E}_{a d s}(\mathrm{HCl})\right|$ is very significanttly correlated with the durability of investigated Palladium catalysts as shown in Figure $6 \mathrm{~b}$. Rises in $\left|\mathrm{E}_{a d s}\left(\mathrm{C}_{2} \mathrm{H}_{2}\right)-\mathrm{E}_{\text {ads }}(\mathrm{HCl})\right|$ paralleled increase in deactivation rates, which implies that the higher durability came from the similar adsorption intensity for acetylene and hydrochlorination. Based on the information discussed above, the approximate adsorption strength to acetylene and hydrogen chloride is beneficial to Pd-based catalyst.

To further understand the intrinsic properties of Pd catalysts, we likewise calculated the Hirshfeld charge of $\mathrm{Pd}$ and $\mathrm{N}$ atoms in $\mathrm{Pd}$-based catalysts, for it can provide the properties and feasible active sites for atoms in catalysts to reserve or release electrons in reaction. Hirshfeld charge on Pd atoms $\left(\mathrm{C}_{H}(\mathrm{Pd})\right)$ all increased with the addition of N-containing ligands (Figure $6 \mathrm{c}$ and Table S3), this implies that the capacity of the Pd atoms to accept electrons is enhanced, thus, the adsorption strength (energy) to acetylene may also enhance. However, the adsorption energy of acetylene was not increased in all $\mathrm{N}$-containing ligands catalysts, in contrast, all $\mathrm{C}_{H}(\mathrm{Pd})$ were enlarged after the adsorption for acetylene. The increase in local Hirshfeld charge of $\mathrm{Pd}$ atoms probably comes from the presence of electron receptor effect brought about by the $\mathrm{N}$-containing ligands, which can be confirmed by the Hirshfeld charge on the $\mathrm{N}$ atom $\left(\mathrm{C}_{H}(\mathrm{~N})\right.$, where $\mathrm{N}$ is derived from nitrogen ligands). As is shown in Figure $6 \mathrm{c}$ and Supplementary Table S3, all $\mathrm{C}_{H}(\mathrm{~N})$ decreased after adsorbing acetylene in $\mathrm{N}$-containing ligands $\mathrm{Pd}$-based catalysts, indicating that partial of electrons were transferred from $\mathrm{Pd}$ atoms to $\mathrm{N}$ atoms during the adsorption. Pd atoms can serve as an electron transfer medium, which electronic properties can be tailored by doping with various $\mathrm{N}$-containing ligands and can transfer the electron that from acetylene to nitrogen ligands during the activation process (Supplementary Figures S3-S6). Taken together, our data provide a new insight into possible strategies for fabricating a stable Pd-based acetylene hydrochlorination catalyst involved in modifying the electronic structure and regulating adsorption behavior.

\subsection{Insights into Pd-2A-IL/AC Catalyst}

It is worth mentioning that Pd-2A-IL/AC catalyst exhibit the highest activity and durability during the reaction. Therefore, we further investigate the Pd-2A-IL/AC catalyst for insight into the mechanism. 
As is shown in Figure $7 \mathrm{c}, \mathrm{d}$, the adsorption energy for acetylene and hydrogen chloride by different $\mathrm{Pd}$ active sites were investigated. Clearly, $\mathrm{C}_{2} \mathrm{H}_{2}$ can strongly be adsorbed by $\mathrm{PdCl}_{2}$ due to the endothermic nature of the adsorption process with the adsorption energy Eads $=-125.02 \mathrm{~kJ} \mathrm{~mol}^{-1}$, which was almost 2 times of $\mathrm{HCl}\left(\right.$ Eads $=-64.65 \mathrm{~kJ} \mathrm{~mol}^{-1}$ ). As for Pd-IL/AC catalyst, the adsorption energy for both acetylene and hydrogen chloride were greatly decreased. However, the adsorption energy for acetylene (Eads $=-29.75 \mathrm{~kJ} \mathrm{~mol}^{-1}$ ) by the Pd active center is still far greater than that of hydrogen chloride $\left(\right.$ Eads $\left.=-14.46 \mathrm{~kJ} \mathrm{~mol}^{-1}\right)$. Therefore, the possibility of reduction or loss of Pd species still exists in long-term catalytic reactions. Zhao et al. reported that about one tenth of the initial Pd component was ran off from Pd-IL/AC catalyst during the reaction process [29], which can be well explained by above calculation results. Encouragingly, with the further modification by N-containing ligands, i.e., Pd-A-IL/AC catalyst, the adsorption ability for $\mathrm{HCl}$ were markedly enhanced (Eads $=-42.75 \mathrm{~kJ} \mathrm{~mol}^{-1}$ ), which was three times of Pd-IL/AC catalyst $\left(\right.$ Eads $\left.=-14.46 \mathrm{~kJ} \mathrm{~mol}^{-1}\right)$. Meanwhile, the adsorption energy for hydrogen chloride was higher than acetylene (Eads $=-26.28 \mathrm{~kJ} \mathrm{~mol}^{-1}$ ). These results imply that, theoretically, the catalyst adsorbs hydrogen chloride preferentially in the reaction, which avoiding the formation of sublimated $\mathrm{PdCl}_{2}-\mathrm{C}_{2} \mathrm{H}_{2}$, thereby greatly inhibiting the leaching of active components.

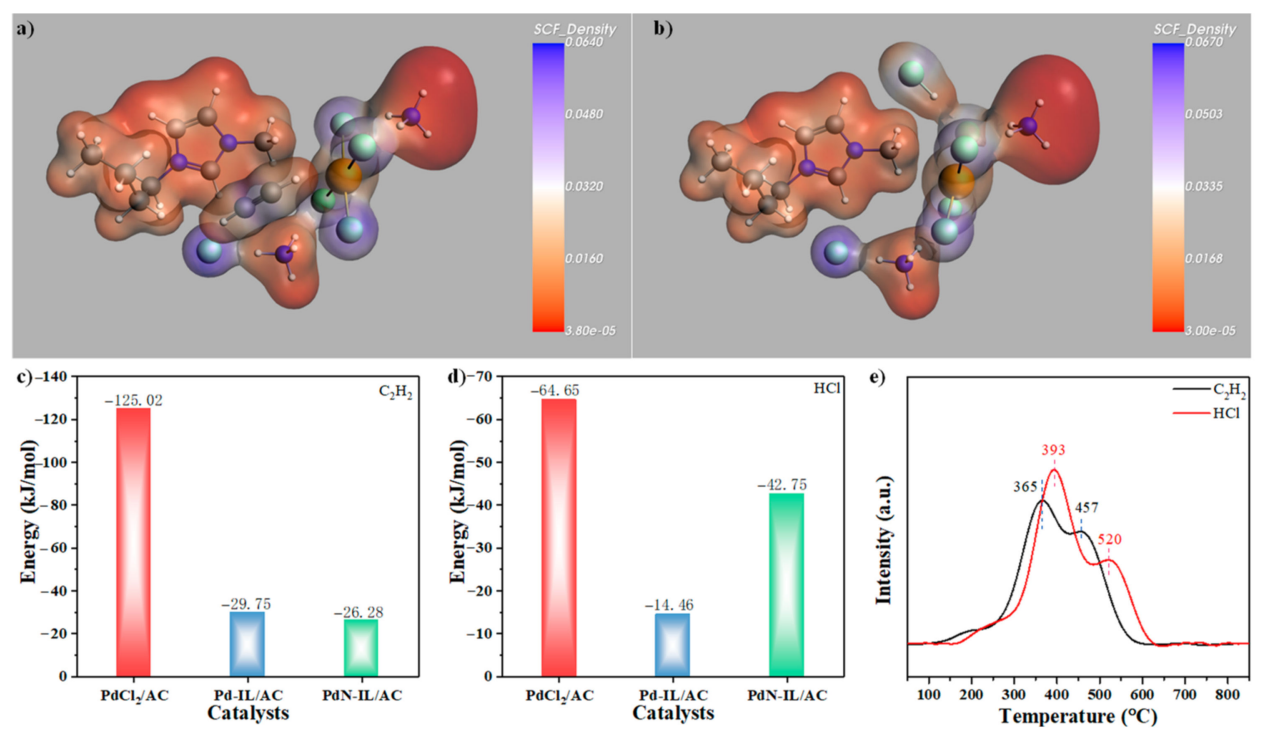

Figure 7. DFT calculations on the activation mechanism. The optimal structures of Pd-A-IL/AC catalyst with (a) $\mathrm{C}_{2} \mathrm{H}_{2}$ and (b) $\mathrm{HCl}$ adsorbed. The adsorption energies of (c) $\mathrm{C}_{2} \mathrm{H}_{2}$ and (d) $\mathrm{HCl}$. (e) TPD profiles of $\mathrm{C}_{2} \mathrm{H}_{2}$ and $\mathrm{HCl}$.

Since the adsorption properties of Pd-A-IL/AC for substrates is well illustrated, we further studied the electronic properties of the Pd active center. The electron density distribution of Pd-2A-IL active center after interacting with acetylene and hydrogen chloride were shown in Figure 7a,b, respectively. From Figure $7 \mathrm{a}$, we can see that the $\mathrm{NH}_{4}{ }^{+}$ligands adopt part of the electrons from $\mathrm{PdCl}_{4}{ }^{2-}$ complexes via Cl-bridges. In typical $\mathrm{Pd}$ catalyzed acetylene hydrochlorination reaction, acetylene adsorbed on $\mathrm{PdCl}_{2}$ active sites, $\mathrm{d}$-cavitation of $\mathrm{Pd} 3 \mathrm{~d}$ accept electrons that donated from the triple bond of acetylene, thus acetylene was greatly activated. However, the electrons transferring from acetylene to Pd were excessive, which leads to an unexpected coordination between them. Surprisingly, in the presence of $\mathrm{NH}_{4}{ }^{+}$, the interaction was efficiently regulated. The $\mathrm{NH}_{4}{ }^{+}$cations act as electron acceptors, which accept excessive electrons. This kind of electron transfer mechanism has an instructive effect on the regulation of the adsorption strength for acetylene. In addition, the activation path of acetylene was completely changed, as is shown, the activation was accomplished under the synergistic effect of $\left(\mathrm{NH}_{4}\right)_{2} \mathrm{PdCl}_{4}$ and ionic liquids. On the basis of the same principle, the adsorption ability of hydrogen chloride on active center is also being strongly controlled, the addition of $\mathrm{NH}_{4}{ }^{+}$along with $\mathrm{PdCl}_{4}{ }^{2-}$ create a favorable environment for adsorption and activation of hydrogen chloride. Moderately 
activated acetylene molecules and enhanced hydrogen chloride transition state make the reaction easier, as could be confirmed by TPD results in Figure 7e.

\section{Materials and Methods}

Pd-based catalysts that loading with $\mathrm{N}$-containing ligands were prepared by impregnation. For example, the $\left(\mathrm{NH}_{4}\right)_{2} \mathrm{PdCl}_{4}$ complex was synthesized according to the literature $[30,66,67]$. First of all, $35.3 \mathrm{mg} \mathrm{H}_{2} \mathrm{PdCl}_{4}$ and a certain amount of $\mathrm{NH}_{4} \mathrm{Cl}$ was dissolved in $8 \mathrm{~mL}$ water at $80^{\circ} \mathrm{C}$ using ultrasound for $60 \mathrm{~min}$ to obtained yellow-brown $\left(\mathrm{NH}_{4}\right)_{2} \mathrm{PdCl}_{4}$ crystals. Then, a certain amount of the $\left(\mathrm{NH}_{4}\right)_{2} \mathrm{PdCl}_{4}$ and 1-butyl-3-methylimidazolium chloride ionic liquids were added in muriatic acid. In the end, $3 \mathrm{~g}$ activated carbon (AC) was mixed with the above prepared liquid accompanying agitation. Then the mixture was dried at $110^{\circ} \mathrm{C}$ for $10 \mathrm{~h}$ to remove water, the prepared catalyst was named as Pd-xA-IL/AC (where $\mathrm{A}$ is the $\mathrm{NH}_{4}{ }^{+}$ligand, $\mathrm{x}$ is the mole ratio between $\mathrm{NH} 4^{+}$and $\mathrm{Pd}$ ). Similar methods were also applied to prepare A/AC, IL/AC, Pd-EDA-IL/AC, Pd-PR-IL/AC, Pd-PD-IL/AC catalysts replacing $\mathrm{NH}_{4}{ }^{+}$with ethylenediamine (EDA), pyrrole (PR) and pyridine (PD), respectively. $\mathrm{Pd} / \mathrm{AC}$ catalyst was directly prepared from $\mathrm{H}_{2} \mathrm{PdCl}_{4}$. Without specifically mentioned, the loading of $\mathrm{Pd}$ in all catalysts were fixed at $0.5 \mathrm{wt} \%$ and the mole ratio of Pd:N-ligands were $1: 2$, the loading of IL in IL-containing catalysts were fixed at $20 \mathrm{wt} \%$. All chemical reagents were bought from Sigma-Aldrich (St. Louis, MO, USA).

Catalytic performance were tested in a heterogenous fixed-bed reactor. At first, nitrogen $\left(\mathrm{N}_{2}\right)$ was used to sweep the reactor for at least half hour to remove impurities, such as water and air. Then, $\mathrm{C}_{2} \mathrm{H}_{2}$ and $\mathrm{HCl}$ were controlled by mass flow controllers and mixed in a gas mixer after cleaning and drying. The obtained products were washed with $\mathrm{NaOH}$ solution to remove the excess $\mathrm{HCl}$ and then analyzed by gas chromatography (GC-9790A, Fuli, Hangzhou, China).

The valence states of Pd were determined by X-ray photoelectron spectroscopy (XPS) on a Kratos AXIS Ultra DLD apparatus (Shimadzu, Kyoto, Japan), selecting Al K $\alpha$ as X-ray source, with a pass-energy of $40 \mathrm{eV}$. Inductively coupled plasma mass spectroscopy (ICP-MS, PerkinElmer Elan DRC-e, Shelton, CT, USA) was taken to determine the Pd loadings in catalysts. The dispersion and particles size of Pd were analyzed by X-ray diffraction (XRD) on a PANalytical X'pert diffractometer (Bruker, Karlsruhe, Germany). HAADF-STEM characterization was carried out on a Tecnai G2 F30 S-Twin electron microscope (FEI, Hillsboro, OR, USA) to investigate the element distribution of catalysts. The TPD was carried out on an AutochemII 2920 (Micromeritics Instrument Ltd., Atlanta, GA, USA) and recorded by gas chromatography. Thermogravimetric analysis (TGA) was conducted with a thermogravimetric differential scanning calorimetry simultaneous analyzer (NETZSCH STA449F5, NETZSCH, Selb, Germany).

In order to investigate the electron structures and adsorption properties of the investigated catalysts, geometry optimization was calculated in the AMS-ADF package, together with the B3LYP-D3 (BJ) functional and TZP corrections [65,68-70].

\section{Conclusions}

In summary, a general strategy is developed to stabilize Pd active components in activated carbon via the synergistic effect of nitrogen ligand and ionic liquids. Meanwhile, a standard for modifying the catalyst electron structure and regulating the adsorption behavior of reactants is also established. In this approach, the addition of N-containing ligands not only changes the adsorption properties of catalysts to substrates, but also modifies the electronic structure of the Pd active center microenvironment. Additionally, the differential energy, $\left|\mathrm{E}_{a d s}\left(\mathrm{C}_{2} \mathrm{H}_{2}\right)-\mathrm{E}_{a d s}(\mathrm{HCl})\right|$, can accurately predict the durability of Pd-based catalyst. Despite its exploratory nature, this study offers some insight into the design principle of highly catalytic active and durable Pd-based catalysts, which reveal the enormous potential of Pd-based catalysts as promising candidates for Chlor-alkali (chlorine alkali) industry industrial applications. 
Supplementary Materials: The following are available online at http://www.mdpi.com/2073-4344/10/1/24/s1, Figure S1: XRD results of fresh and used Pd/AC and Pd-IL/AC catalysts, Figure S2: XPS spectra of fresh and used $\mathrm{Pd} / \mathrm{AC}$ and Pd-IL/AC catalysts, Figure S3: The electron density of (a) Pd-2A-IL; (b) Pd-2A-IL-C ${ }_{2} \mathrm{H}_{2} ;(\mathbf{c})$ Pd-2A-IL-HCl, Figure S4: The electron density of (a) Pd-2EDA-IL; (b) Pd-2EDA-IL-C ${ }_{2} \mathrm{H}_{2}$; (c) Pd-2EDA-IL-HCl, Figure S5: The electron density of (a) Pd-2PR-IL; (b) Pd-2PR-IL- $\mathrm{C}_{2} \mathrm{H}_{2} ;$ (c) Pd-2PR-IL-HCl, Figure S6: The electron density of (a) Pd-2PD-IL; (b) Pd-2PD-IL- $\mathrm{C}_{2} \mathrm{H}_{2}$; (c) Pd-2PD-IL-HCl, Table S1: The comparisons of catalytic performance of various catalysts reported in literatures. Table $\mathrm{S} 2$. Parameters for the $\mathrm{C}_{2} \mathrm{H}_{2}$ and $\mathrm{HCl}$ molecules adsorption on Pd-based catalysts: adsorption energy $\left(\mathrm{E}_{\mathrm{ads}}\right)$, bond length of the adsorbed molecule $\left(\mathrm{d}_{\mathrm{C}-\mathrm{C}}\right.$ or $\left.\mathrm{d}_{\mathrm{H}-\mathrm{Cl}}\right)$. Table S3. Parameters for the $\mathrm{C}_{2} \mathrm{H}_{2}$ and $\mathrm{HCl}$ molecules adsorption on Pd-based catalysts: Hirshfeld charge $\left(\mathrm{C}_{\mathrm{H}}\right)$, bond length of the adsorbed molecule $\left(\mathrm{d}_{\mathrm{C}-\mathrm{C}}\right.$ or $\left.\mathrm{d}_{\mathrm{H}-\mathrm{Cl}}\right)$.

Author Contributions: Y.C. and J.Z. conceived and designed the experiments; B.W. and S.W. performed the experiments: C.J., Y.Y., Z.-T.H., J.L. and L.G. contributed reagents/materials/analysis tools; Y.C. and Y.Y. wrote the paper. All authors have read and agreed to the published version of the manuscript.

Funding: Financial support supported by the National Natural Science Foundation of China (NSFC; Grant $21606199,21476207)$ is gratefully acknowledged.

Conflicts of Interest: The authors declare no conflict of interest.

\section{References}

1. Johnston, P.; Carthey, N.; Hutchings, G.J. Discovery, development, and commercialization of gold catalysts for acetylene hydrochlorination. J. Am. Chem. Soc. 2015, 137, 14548-14557. [CrossRef] [PubMed]

2. Malta, G.; Kondrat, S.A.; Freakley, S.J.; Davies, C.J.; Dawson, S.; Liu, X.; Lu, L.; Dymkowski, K.; Fernandez-Alonso, F.; Mukhopadhyay, S. Deactivation of a single-site gold-on-carbon acetylene hydrochlorination catalyst: An X-ray absorption and inelastic neutron scattering study. ACS Catal. 2018, 8, 8493-8505. [CrossRef]

3. Schobert, H. Production of acetylene and acetylene-based chemicals from coal. Chem. Rev. 2014, 114, 1743-1760. [CrossRef] [PubMed]

4. Zhong, J.; Xu, Y.; Liu, Z. Heterogeneous non-mercury catalysts for acetylene hydrochlorination progress, challenges, and opportunities. Green Chem. 2018, 20, 2412-2427. [CrossRef]

5. Lin, R.; Amrute, A.P.; Perez-Ramirez, J. Halogen-mediated conversion of hydrocarbons to commodities. Chem. Rev. 2017, 117, 4182-4247. [CrossRef]

6. Lan, G.; Wang, Y.; Qiu, Y.; Wang, X.; Liang, J.; Han, W.; Tang, H.-D.; Liu, H.; Liu, J.; Li, Y. Wheat flour derived $\mathrm{N}$-doped mesoporous carbons extrudate as superior metal-free catalysts for acetylene hydrochlorination. Chem. Commun. 2017, 54, 623-626. [CrossRef]

7. Anastas, P.; Eghbali, N. Green chemistry: Principles and practice. Chem. Soc. Rev. 2010, 39, 301-312. [CrossRef]

8. Hutchings, G.J. Nanocrystalline gold and gold palladium alloy catalysts for chemical synthesis. Chem. Commun. 2008, 10, 1148-1164. [CrossRef]

9. Shang, S.; Zhao, W.; Wang, Y.; Li, X.; Zhang, J.; Han, Y.; Li, W. Highly efficient Ru@IL/AC to substitute mercuric catalyst for acetylene hydrochlorination. ACS Catal. 2017, 7, 3510-3520. [CrossRef]

10. Zhang, H.; Li, W.; Jin, Y.; Sheng, W.; Hui, M.; Wang, X.; Zhang, J. Ru-Co(III)-Cu(II)/SAC catalyst for acetylene hydrochlorination. Appl. Catal. B Environ. 2016, 189, 56-64. [CrossRef]

11. Panova, S.A.; Shestakov, G.K.; Temkin, O.N. Supported liquid-phase rhodium catalyst for acetylene hydrochlorination. J. Chem. Soc. Chem. Commun. 1994, 7, 977. [CrossRef]

12. Zhao, J.; Zhang, T.; Di, X.; Xu, J.; Gu, S.; Zhang, Q.; Ni, J.; Li, X. Activated carbon supported ternary gold-cesium(I)-indium(III) catalyst for the hydrochlorination of acetylene. Catal. Sci. Technol. 2015, 5, 4973-4984. [CrossRef]

13. Zhao, J.; Xu, J.; Xu, J.; Ni, J.; Zhang, T.; Xu, X.; Li, X. Activated-carbon-supported gold-cesium(I) as highly effective catalysts for hydrochlorination of acetylene to vinyl chloride. ChemPlusChem 2015, 80, 196-201. [CrossRef]

14. Zhao, J.; Zhang, T.; Di, X.; Xu, J.; Xu, J.; Feng, F.; Ni, J.; Li, X. Nitrogen-modified activated carbon supported bimetallic gold-cesium(I) as highly active and stable catalyst for the hydrochlorination of acetylene. RSC Adv. 2015, 5, 6925-6931. [CrossRef] 
15. Li, J.; Fan, J.; Ali, S.; Lan, G.; Tang, H.; Han, W.; Liu, H.; Li, B.; Li, Y. The origin of the extraordinary stability of mercury catalysts on the carbon support: the synergy effects between oxygen groups and defects revealed from a combined experimental and DFT study. Chin. J. Catal. 2019, 40,141-146. [CrossRef]

16. Zhai, Y.; Zhao, J.; Di, X.; Di, S.; Wang, B.; Yue, Y.; Sheng, G.; Lai, H.; Guo, L.; Wang, H.; et al. Carbon supported perovskite-like $\mathrm{CsCuCl}_{3}$ nanoparticles: A highly active and cost-effective heterogeneous catalyst in the hydrochlorination of acetylene to vinyl chloride. Catal. Sci. Technol. 2018, 8, 2901-2908. [CrossRef]

17. Krasnyakova, T.V.; Zhikharev, I.V.; Mitchenko, R.S.; Burkhovetski, V.I.; Korduban, A.M.; Kryshchuk, T.V.; Mitchenko, S.A. Acetylene catalytic hydrochlorination over mechanically pre-activated $\mathrm{K}_{2} \mathrm{PdCl}_{4}$ salt: A study of the reaction mechanism. J. Catal. 2012, 288, 33-43. [CrossRef]

18. Qin, G.; Song, Y.; Jin, R.; Shi, J.; Yu, Z.; Cao, S. Gas-liquid acetylene hydrochlorination under nonmercuric catalysis using ionic liquids as reaction media. Green Chem. 2011, 13, 1495-1498. [CrossRef]

19. Zhao, W.; Zhu, M.; Dai, B. Cobalt-nitrogen-activated carbon as catalyst in acetylene hydrochlorination. Catal. Commun. 2017, 98, 22-25. [CrossRef]

20. Wang, B.; Lai, H.; Yue, Y.; Sheng, G.; Deng, Y.; He, H.; Guo, L.; Zhao, J.; Li, X. Zeolite supported ionic liquid catalysts for the hydrochlorination of acetylene. Catalysts 2018, 8, 351-364. [CrossRef]

21. Zhao, J.; Yu, Y.; Xu, X.; Di, S.; Wang, B.; Xu, H.; Ni, J.; Guo, L.; Pan, Z.; Li, X. Stabilizing Au(III) in supported-ionic-liquid-phase (SILP) catalyst using $\mathrm{CuCl}_{2}$ via a redox mechanism. Appl. Catal. B Environ. 2017, 206, 175-183. [CrossRef]

22. Li, X.; Pan, X.; Yu, L.; Ren, P.; Wu, X.; Sun, L.; Jiao, F.; Bao, X. Silicon carbide-derived carbon nanocomposite as a substitute for mercury in the catalytic hydrochlorination of acetylene. Nat. Commun. 2014, 5, 3688-3695. [CrossRef] [PubMed]

23. Lin, R.; Kaiser, S.K.; Hauert, R.; Pérez-Ramírez, J. Descriptors for high-performance nitrogen-doped carbon catalysts in acetylene hydrochlorination. ACS Catal. 2018, 8, 1114-1121. [CrossRef]

24. Song, Z.; Liu, G.; He, D.; Pang, X.; Tong, Y.; Wu, Y.; Yuan, D.; Liu, Z.; Xu, Y. Acetylene hydrochlorination over 13X zeolite catalysts at high temperature. Green Chem. 2016, 18, 5994-5998. [CrossRef]

25. Zhao, J.; Gu, S.; Xu, X.; Zhang, T.; Di, X.; Pan, Z.; Li, X. Promotional effect of copper(II) on an activated carbon supported low content bimetallic gold-cesium(I) catalyst in acetylene hydrochlorination. RSC Adv. 2015, 5, 101427-101436. [CrossRef]

26. Zhao, J.; Wang, B.; Yue, Y.; Di, S.; Zhai, Y.; He, H.; Sheng, G.; Lai, H.; Zhu, Y.; Guo, L.; et al. Towards a greener approach for the preparation of highly active gold/carbon catalyst for the hydrochlorination of ethyne. J. Catal. 2018, 365, 153-162. [CrossRef]

27. Zhao, J.; Gu, S.; Xu, X.; Zhang, T.; Yu, Y.; Di, X.; Ni, J.; Pan, Y.; Li, X. Supported ionic-liquid-phase-stabilized $\mathrm{Au}(\mathrm{III})$ catalyst for acetylene hydrochlorination. Catal. Sci. Technol. 2016, 6, 3263-3270. [CrossRef]

28. Zhao, J.; Wang, B.; Xu, X.; Yu, Y.; Di, S.; Xu, H.; Zhai, Y.; He, H.; Guo, L.; Pan, Z.; et al. Alternative solvent to aqua regia to activate $\mathrm{Au} / \mathrm{AC}$ catalysts for the hydrochlorination of acetylene. J. Catal. 2017, 350, 149-158. [CrossRef]

29. Zhao, J.; Yue, Y.; Sheng, G.; Wang, B.; Lai, H.; Di, S.; Zhai, Y.; Guo, L.; Li, X. Supported ionic liquid-palladium catalyst for the highly effective hydrochlorination of acetylene. Chem. Eng. J. 2019, 360, 38-46. [CrossRef]

30. He, H.; Zhao, J.; Wang, B.; Yue, Y.; Sheng, G.; Wang, Q.; Yu, L.; Hu, Z.-T.; Li, X. Design strategies for the development of a Pd-based acetylene hydrochlorination catalyst: Improvement of catalyst stability by nitrogencontaining ligands. RSC Adv. 2019, 9, 21557-21563. [CrossRef]

31. Zhao, J.; Xu, J.; Xu, J.; Zhang, T.; Di, X.; Ni, j.; Li, X. Enhancement of Au/AC acetylene hydrochlorination catalyst activity and stability via nitrogen-modified activated carbon support. Chem. Eng. J. 2015, 262, 1152-1160. [CrossRef]

32. Wang, B.; Zhao, J.; Yue, Y.; Sheng, G.; Lai, H.; Rui, J.; He, H.; Hu, Z.; Feng, F.; Zhang, Q.; et al. Carbon with surface-enriched nitrogen and sulfur supported au catalysts for acetylene hydrochlorination. ChemCatChem 2019, 11, 1002-1009. [CrossRef]

33. Zhao, J.; Wang, B.; Yue, Y.; Sheng, G.; Lai, H.; Wang, S.; Yu, L.; Zhang, Q.; Feng, F.; Hu, Z.-T.; et al. Nitrogenand phosphorus-codoped carbon-based catalyst for acetylene Hydrochlorination. J. Catal. 2019, 373, $240-249$. [CrossRef]

34. Lai, H.; Wang, B.; Yue, Y.; Sheng, G.; Wang, S.; Feng, F.; Zhang, Q.; Zhao, J.; Li, X. An alternative carbon carrier in green preparation of efficient gold/carbon catalyst for acetylene hydrochlorination. ChemCatChem 2019, 11, 3318-3326. [CrossRef] 
35. Nkosi, B.; Coville, N.J.; Hutchings, G.J. Vapour phase hydrochlorination of acetylene with group VIII and IB metal chloride catalysts. Appl. Catal. 1988, 43, 33-39. [CrossRef]

36. Song, Q.; Wang, S.; Shen, B.; Zhao, J. Palladium-based catalysts for the hydrochlorination of acetylene: reasons for deactivation and its regeneration. Petrol. Sci. Technol. 2010, 28, 1825-1833. [CrossRef]

37. Wang, L.; Wang, F.; Wang, J.; Tang, X.; Zhao, Y.; Yang, D.; Jia, F.; Hao, T. Hydrochlorination of acetylene to vinyl chloride over Pd supported on zeolite Y. React. Kinet. Mech. Catal. 2013, 110, 187-194. [CrossRef]

38. Wang, F.; Wang, L.; Wang, J.; Zhao, Y.; Wang, Y.; Yang, D. Bimetallic Pd-K/Y-zeolite catalyst in acetylene hydrochlorination for PVC production. React. Kinet. Mech. Catal. 2014, 114, 725-734. [CrossRef]

39. Wang, L.; Wang, F.; Wang, J. Catalytic properties of $\mathrm{Pd} / \mathrm{HY}$ catalysts modified with $\mathrm{NH}_{4} \mathrm{~F}$ for acetylene hydrochlorination. Catal. Commun. 2015, 65, 41-45. [CrossRef]

40. Wang, L.; Wang, F.; Wang, J. Effect of $\mathrm{K}$ promoter on the stability of Pd/NFY catalysts for acetylene hydrochlorination. Catal. Commun. 2016, 83, 9-13. [CrossRef]

41. Wang, L.; Wang, F.; Wang, J. Enhanced stability of hydrochlorination of acetylene using polyaniline- modified $\mathrm{Pd} / \mathrm{HY}$ catalysts. Catal. Commun. 2016, 74, 55-59. [CrossRef]

42. Wang, L.; Wang, F.; Wang, J. Non-mercury catalytic acetylene hydrochlorination over the $\mathrm{NH}_{4}$ F-Urea-modified $\mathrm{Pd} / \mathrm{HY}$ catalyst for vinylchloride monomer production. New J. Chem. 2016, 40, 3019-3023. [CrossRef]

43. Gesi, K. Dielectric study on the phase transition in $\left(\mathrm{NH}_{4}\right)_{2} \mathrm{PdCl}_{4}$ and $\left(\mathrm{ND}_{4}\right)_{2} \mathrm{PdCl}_{4}$. Ferroelectrics 2001, 262, 143-148. [CrossRef]

44. Di, X.; Zhao, J.; Yu, Y.; Xu, X.; Gu, S.; He, H.; Zhang, T.; Li, X. One-pot synthesis of nitrogen and sulfur co-doped activated carbon supported $\mathrm{AuCl}_{3}$ as efficient catalysts for acetylene hydrochlorination. Chin. Chem. Lett. 2016, 27, 1567-1571. [CrossRef]

45. Zhou, K.; Li, B.; Zhang, Q.; Huang, J.; Tian, G.; Jia, J.; Zhao, M.; Luo, G.; Su, D.; Wei, F. The catalytic pathways of hydrohalogenation over metal-free nitrogen-doped carbon nanotubes. ChemSusChem 2014, 7, 723-729. [CrossRef] [PubMed]

46. Conte, M.; Carley, A.; Attard, G.; Herzing, A.; Kiely, C.; Hutchings, G.J. Hydrochlorination of acetylene using supported bimetallic Au-based catalysts. J. Catal. 2008, 257, 190-198. [CrossRef]

47. Zhang, H.; Dai, B.; Wang, X.; Li, W.; Han, Y.; Gu, J.; Zhang, J. Non-mercury catalytic acetylene hydrochlorination over bimetallic Au-Co(III)/SAC catalysts for vinyl chloride monomer production. Green Chem. 2013, 15, 829-836. [CrossRef]

48. Zheng, W.; Hu, W.; Wang, W.; Xu, Y.; Wang, X.; Xia, R.; Li, J.; Zhang, C.; Pang, X.; Xie, D.; et al. A Low Content Gold Complex Catalyst for Acetylene Hydrochlorination. Chinese Patent CN201310146639, 25 April 2013.

49. Luo, G.; Zhou, K.; Wei, F.; Si, J.; Li, C.; Zhou, J. A Catalyst Supported on Nitrogen Doped Carbon Material. Chinese Patent CN201310289144.9, 10 July 2013.

50. Yang, X.; Jiang, C.; Yang, Z.; Zhang, J. Hydrochlorination of acetylene using SiC foam supported structured C/Au catalysts. Mater. Sci. Technol. 2014, 30, 434-440. [CrossRef]

51. Conte, M.; Davies, C.J.; Morgan, D.J.; Davies, T.E.; Elias, D.J.; Carley, A.F.; Johnston, P.; Hutchings, G.J. Aqua regia activated $\mathrm{Au} / \mathrm{C}$ catalysts for the hydrochlorination of acetylene. J. Catal. 2013, 297, 128-136. [CrossRef]

52. Tian, X.; Hong, G.; Liu, Y.; Jiang, B.; Yang, Y. Catalytic performance of Au(III) supported on $\mathrm{SiO}_{2}$ modified activated carbon. RSC Adv. 2014, 4, 36316-36324. [CrossRef]

53. Nkosi, B.; Coville, N.J.; Hutchings, G.J. Reactivation of a supported gold catalyst for acetylene hydrochlorination. J. Chem. Soc. Chem. Commun. 1988, 71-72. [CrossRef]

54. Huang, C.; Zhu, M.; Kang, L.; Li, X.; Dai, B. Active carbon supported $\mathrm{TiO}_{2}-\mathrm{AuCl}_{3} / \mathrm{AC}$ catalyst with excellent stability for acetylene hydrochlorination reaction. Chem. Eng. J. 2014, 242, 69-75. [CrossRef]

55. Wittanadecha, W.; Laosiripojana, N.; Ketcong, A.; Ningnuek, N.; Praserthdam, P.; Monnier, J.R.; Assabumrungrat, $\mathrm{S}$. Preparation of $\mathrm{Au} / \mathrm{C}$ catalysts using microwave-assisted and ultrasonic-assisted methods for acetylene hydrochlorination. React. Kinet. Mech. Catal. 2014, 112, 189-198. [CrossRef]

56. Huang, C.; Zhu, M.; Kang, L.; Dai, B. A novel high-stability Au(III)/Schiff-based catalyst for acetylene hydrochlorination reaction. Catal. Commun. 2014, 54, 61-65. [CrossRef]

57. Wang, B.; Yu, L.; Zhang, J.; Pu, Y.; Zhang, H.; Li, W. Phosphorus-doped carbon supports enhance gold-based catalysts for acetylene hydrochlorination. RSC Adv. 2014, 4, 15877-15885. [CrossRef]

58. Dong, Y.; Zhang, H.; Li, W.; Sun, M.; Guo, C.; Zhang, J. Bimetallic Au-Sn/AC catalysts for acetylene hydrochlorination. J. Ind. Eng. Chem. 2016, 35, 177-184. [CrossRef] 
59. Ke, J.; Zhao, Y.; Yin, Y.; Chen, K.; Duan, X.; Ye, L.; Yuan, Y. Yttrium chloride-modified Au/AC catalysts for acetylene hydrochlorination with improved activity and stability. J. Rare Earths 2017, 35, 1083-1091. [CrossRef]

60. Zhou, K.; Jia, J.; Li, C.; Xu, H.; Zhou, J.; Luo, G.; Wei, F. A low content Au-based catalyst for hydrochlorination of $\mathrm{C}_{2} \mathrm{H}_{2}$ and its industrial scale-up for future PVC processes. Green Chem. 2015, 17, 356-364. [CrossRef]

61. Hu, J.; Yang, Q.; Yang, L.; Zhang, Z.; Su, B.; Bao, Z.; Ren, Q.; Xing, H.; Dai, S. Confining noble metal (Pd, Au, $\mathrm{Pt})$ nanoparticles in surfactant ionic liquids: Active non-mercury catalysts for hydrochlorination of acetylene. ACS Catal. 2015, 5, 6724-6731. [CrossRef]

62. Ordóñez, S.; Díez, F.V.; Sastre, H. Characterisation of the deactivation of platinum and palladium supported on activated carbon used as hydrodechlorination catalysts. Appl. Catal. B Environ. 2001, 31, 113-122. [CrossRef]

63. Zhao, J.; Xu, X.; Li, X.; Wang, J.G. Promotion of Sn on the Pd/AC catalyst for the selective hydrogenation of cinnamaldehyde. Catal. Commun. 2014, 43, 102-106. [CrossRef]

64. Liu, Y.; Li, Z.; Yu, Q.; Chen, Y.; Chai, Z.; Zhao, G.; Liu, S.; Cheong, W.-C.; Pan, Y.; Zhang, Q.; et al. A general strategy for fabricating isolated single metal atomic site catalysts in Y zeolite. J. Am. Chem. Soc. 2019, 141, 9305-9311. [CrossRef] [PubMed]

65. Yue, Y.; Wang, B.; Sheng, G.; Lai, H.; Wang, S.; Chen, Z.; Hu, Z.-T.; Zhao, J.; Li, X. An ultra-high $\mathrm{H}_{2} \mathrm{~S}-$ resistant gold-based imidazolium ionic liquid catalyst for acetylene hydrochlorination. New J. Chem. 2019, 43, 12767-12775. [CrossRef]

66. Denuault, G.; Milhano, C.; Pletcher, D. Mesoporous palladium-the surface electrochemistry of palladium in aqueous sodium hydroxide and the cathodic reduction of nitrite. Phys. Chem. Chem. Phys. 2005, 7, 3545-3551. [CrossRef]

67. Van der Lubbe, S.C.C.; Zaccaria, F.; Sun, X.; Guerra, C.F. Secondary electrostatic interaction model revised: prediction comes mainly from measuring charge accumulation in hydrogenbonded monomers. J. Am. Chem. Soc. 2019, 141, 4878-4885. [CrossRef]

68. Zhang, S.-S.; Alkan, F.; Su, H.-F.; Aikens, C.M.; Tung, C.-H.; Sun, D. $\left[\mathrm{Ag}_{48}\left(\mathrm{C} \equiv \mathrm{C}^{t} \mathrm{Bu}\right)_{20}\left(\mathrm{CrO}_{4}\right)_{7}\right]$ : An atomically precise silver nanocluster co-protected by inorganic and organic ligands. J. Am. Chem. Soc. 2019, 141, 4460-4467. [CrossRef]

69. Lei, Z.; Dai, C.; Chen, B. Gas solubility in ionic liquids. Chem. Rev. 2014, 114, 1289-1326. [CrossRef]

70. Xu, H.; Luo, G. Green production of PVC from laboratory to industrialization: State-of-the-art review of heterogeneous non-mercury catalysts for acetylene hydrochlorination. J. Ind. Eng. Chem. 2018, 65, 13-25. [CrossRef]

(C) 2019 by the authors. Licensee MDPI, Basel, Switzerland. This article is an open access article distributed under the terms and conditions of the Creative Commons Attribution (CC BY) license (http://creativecommons.org/licenses/by/4.0/). 